\title{
The significance of interfamilial relationships on birth preparedness and complication readiness in Pakistan.
}

GHANI, U., CROWTHER, S., KAMAL, Y., WAHAB, M. 
Original Research - Quantitative

\title{
The significance of interfamilial relationships on birth preparedness and complication readiness in Pakistan
}

\author{
Usman Ghani ${ }^{\mathrm{a}, *}$, Susan Crowther ${ }^{\mathrm{b}}$, Yasir Kamal ${ }^{\mathrm{a}}$, Muhammad Wahab ${ }^{\mathrm{a}}$ \\ a Institute of Management Sciences, Peshawar, Pakistan \\ ${ }^{\mathrm{b}}$ Robert Gordon University, Aberdeen, United Kingdom
}

\section{A R T I C L E I N F O}

\section{Article history:}

Received 17 November 2017

Received in revised form 17 February 2018

Accepted 16 March 2018

Available online $\mathrm{xxx}$

\section{Keywords:}

Birth preparedness

Complication readiness

Socio-economic factors

Relationships

Family

\begin{abstract}
A B S T R A C T
Background: In the interests of improving maternal health care and survival, the issue of birth preparedness and complication readiness has been much debated and has remained a priority for the international health community. The provision of birth preparedness and complications readiness is determined by a range of different factors.

Aim: The main aim of this study is to identify and measure the influence of husbands and other family relationships on birth preparedness and complications readiness in the Khyber Pakhtunkhwa province of Pakistan.

Methods: This study is a cross-sectional exploratory study. Data was collected through a survey questionnaire. Logistic regression and descriptive analysis was used.

Findings: Analysis indicated that the mother-in-law's role, men's and women's level of education and interfamilial relationships are still the most significant factors influencing birth preparedness and complications readiness. Of the respondents, $86 \%$ were receiving antenatal care and $76.5 \%$ were planning for the birth to take place in state-run hospitals or private obstetric and gynae clinics.

Conclusion: The tendency to take up antenatal care in Khyber Pakhtunkhwa can mainly be credited to a mutual understanding between husband and wife and a good relationship between the woman and her mother-in-law. Highlighting the significance of these relationships has implications for ensuring birth preparedness and complications readiness.
\end{abstract}

(c) 2018 Australian College of Midwives. Published by Elsevier Ltd. All rights reserved.

\section{Statement of significance}

\section{Problem or issue}

Access to birth preparedness and complication readiness (BPCR) strategies are crucial for ensuring maternal wellbeing and survival.

\section{What is already known}

Provision of BPCR is determined by a range of different factors. Lack of maternal autonomy and the influential role various family members play in the decision-making about access to BPCR remains problematic in some regions.

\footnotetext{
* Corresponding author.

E-mail address: usman.ghani@imsciences.edu.pk (U. Ghani).
}

\section{What this paper adds}

Evidence suggests that level of education and interfamilial relationships are still significant factors influencing uptake of antenatal care and BPCR. Maternity care providers need to be aware of these challenges because they can actively contribute to the moral, motivational and cultural alignment with decision makers within families.

\section{Introduction}

Internationally, researchers have determined that women are more likely to take up antenatal care and give birth in a health institution if they are in a younger age group, have a higher level of education, have a husband with a higher level of education, have a higher income, have more autonomy and live near to a health centre. $^{1-3}$ Awareness of these factors may help stakeholders to develop appropriate plans to help reduce the maternal mortality rate. However, one dynamic factor that has been less investigated 
is interfamilial relationships and their influence on birth preparedness and complication readiness (BPCR). This is particularly pertinent when examining regions in the world where there remains high maternal mortality and where all potential strategies need to be employed to lessen this human misery.

Pakistan is one of six developing countries that make up 50\% of the world's maternal deaths. ${ }^{4}$ As per World Bank data of 2015, it currently has a maternal mortality rate of 178 per 100,000 live births. This rate has improved since 1990 , when rates of 431 per 100,000 live births were reported, as sustained effort has been made to reach the millennium development goal of reducing maternal deaths by seventy five percent. The factors that contribute to a high maternal death rate have been thoroughly explored in the literature of several developing countries, 5,6 including Pakistan. ${ }^{6}$

Pakistan is a patriarchal society with clearly delineated gender roles. ${ }^{7}$ Women are homemakers whose security within the marital family largely depends on 'reproduction of the patrilineal' lineage. Men are the economic providers and decision-makers in most regards, and marriages are typically arranged. ${ }^{8}$ The institutions of purdah (social practice of female seclusion) and izzat (family honour) also play an important role in gender differentials. ${ }^{9}$ Reproductive matters are directly related to sexual relations; thus, they are considered 'shameful' and there is a 'culture of silence' regarding pregnancy and reproduction in most Pakistani communities. ${ }^{10}$ Usually, decisions about reproductive matters are in the hands of the mother-in-law or other men who are older than the husband. ${ }^{7}$ This means that the husband and wife are distanced from the decision-making process regarding reproductive care. Women do not usually leave the home during pregnancy, because pregnancy is understood to be a manifestation of sexual relations and is associated with 'sharam' (i.e., shame). Expectant woman should not appear in public places and therefore their travelling to antenatal care services is particularly problematic. ${ }^{7}$

\subsection{Birth preparedness and complication readiness (BPCR)}

BPCR can be defined as a "comprehensive strategy aimed at promoting the timely utilization of skilled maternal and neonatal health care'.11 Appropriate BPCR can reduce the number of maternal deaths. The John Hopkins Program for International Education in Gynecology and Obstetrics (JHPIEGO) ${ }^{12}$ created the BPCR shared responsibilities matrix, which further defines it as a process in which women, their husbands and their families (a) identify a skilled birth attendant and know how to contact and reach him or her, (b) identify a place for the birth to happen, (c) prepare items for the delivery, (d) attend antenatal care visits, (e) know the danger signs that signal maternal complications and implement a complication readiness plan, (f) know where to go and how to get there for help during the delivery or in an emergency, ( $g$ ) save money for the delivery and emergency situations, and (h) identify a blood donor. ${ }^{12}$ Preparing adequately by following these guidelines can greatly improve a woman's chance of survival. Moreover, according to the United Nations Development Programme (UNDP), ${ }^{13}$ using antenatal care and having skilled attendance at the birth have been shown to reduce maternal mortality.

To fully understand how family dynamics play a role in BPCR, it is important to investigate the relationships between women, their husbands and their mothers-in-law within the contextual realities of a region. In this study, we investigate the determinants of antenatal care use and institutional delivery within the context of a province within Pakistan. Understanding the decision-making process and how power shifts in the family in different cultural situations will help us better understand how to improve the understanding of BPCR among women and their families. This, in turn, will help to counter the negative forces at play by making appropriate plans of action. The following review of the literature explores these issues in more depth to build a clear understanding and define specific objectives for this study.

\subsection{Context: maternal health care in Pakistan}

According to the demographic health survey carried out by the National Institute of Population Studies in Pakistan and Macro International Inc. in $2006,61 \%$ of women received antenatal care and $34 \%$ of women gave birth in a health facility (referred to in this paper as institutional delivery). ${ }^{14}$ Moreover, a recent demographic health survey report, conducted in 2013, indicates that these numbers have increased to $73 \%$ and $48 \%$, respectively. ${ }^{15}$

These improvements may be due to a concerted effort by the government, which launched the Maternal, Newborn and Child Health programme in 2005 with the objective of lowering Pakistan's maternal mortality rate to 140 per 100,000 live births. ${ }^{16}$ This programme supported prenatal, postnatal and newborn care; birth preparedness; skilled birth attendance; and the primary and secondary levels of health care. A Lady Health Worker programme was also initiated in which female health workers were assigned to each geographic area to keep track of pregnant women and their health care and to raise awareness of antenatal and birth services among women. Each health worker was to provide services to a population of 1000 woman. In addition, it is noted that in Pakistan, $70 \%$ of the health-care sector is made up of private hospitals; therefore, private hospitals have a substantial impact on the country's health services. ${ }^{17}$

\subsection{Maternal health care in Khyber Pakhtunkhwa}

In the Khyber Pakhtunkhwa province of Pakistan, the percentage of women receiving maternal health care is lower than in all the other provinces except Baluchistan. ${ }^{15}$ For example, $60.5 \%$ of women receive at least one antenatal care visit by a skilled attendant and $40.5 \%$ give birth in a health facility. These figures are very low in comparison with those for Islamabad (94.3\% and $86.4 \%$, respectively). ${ }^{15}$ This suggests that more attention needs to be focused on the Khyber Pakhtunkhwa province. However, to understand how best to improve the situation, we must better understand the complicated interfamilial relationships and the roles each member plays in households in Khyber Pakhtunkhwa.

\subsection{Influence of women's autonomy}

According to Agha and Carton ${ }^{3}$ the status of women's autonomy in a society is an important determinant of maternal health. Repeatedly, it has been shown that societies that empower women to make their own decisions result in improvements in maternal care. ${ }^{13}$ For example, several studies have shown that there is an association between higher education levels among women and greater use of antenatal care and institutional delivery. ${ }^{13}$ Although associations have been found between women's autonomy, access to education provision and maternal care, ${ }^{3}$ the relationship may be more complex than originally thought.

There is a large volume of literature on women's autonomy and its relationship with maternal care. For example, White et al. found that lower levels of female autonomy are associated with lower uptake of maternal care services and that women's perception of greater self-efficacy is positively associated with institutional delivery. ${ }^{3}$ Agha and Carton conducted a study in Pakistan and found that higher autonomy among women was positively associated with the take-up of antenatal care and institutional delivery. ${ }^{3}$ They used factor analysis to create an autonomy score. 
However, Mumtaz and Salway ${ }^{7}$ do not support the creation of a single autonomy scale for antenatal care judgments; they argue that it is not possible to know the effect of individual aspects combined into one scale. ${ }^{7}$ To support their argument, they point to a study of Bloom et al., ${ }^{18}$ that was conducted in Uttar Pradesh, India, in which the effect of women's autonomy (measured by control over finances, decision-making power and freedom of movement) was found to influence the increased use of antenatal care. $^{18}$ As part of the larger study data was collected from November 1995 to April 1996. The results of the Indian study indicated that only one variable (freedom of movement) was positively associated with the use of antenatal care. Mumtaz and Salway also cautioned against the use of 'Western-based notions of female autonomy' in the Pakistani context. ${ }^{7}$ Instead, in their study, Mumtaz and Salway ${ }^{7}$ looked at five dimensions of women's gendered position: decision-making, access to financial resources, mobility, communication with the husband, and information and knowledge. They found that there was no association between women's involvement in decision-making and their use of antenatal care. ${ }^{7}$ This suggests that women's autonomy may play a much smaller role in the context of Pakistan than it does in other societies, yet this remains unclear.

\subsection{Role of husbands in maternal health care}

With an apparent trend in male involvement in childbirth men's role in maternal health care is another important issue globally, yet this in itself becomes confounded when examined within patriarchal based societies. Male-dominated relationships often influence the care of women in many cultures, and this is especially true in African and Asian countries, such as Nepal. ${ }^{19}$ In African countries, men often decide when to have sexual relations, grant permission for the wife to leave the home, determine how large the family will be and decide if a wife will receive health care and where this will be provided. ${ }^{20}$ In a study in Kenya, very few men (24.9\%) had knowledge of the complications that can occur during a pregnancy, and most indicated that pregnancy is a woman's affair and they are not involved in it. ${ }^{2}$ Men also saw pregnancy as a natural phenomenon that requires no further input from them. Some of the men in the Kenyan study even stated that societal pressure to stay uninvolved was high, as they would be thought to be ruled by their wives if they participated in childbirth issues. The men also insisted that their wives give birth at home due to cultural beliefs that the baby may be bewitched if born outside the home. Added to this, men who accompanied their wives to health facilities were chastised and seen as less of a man.

Some of the findings in the above African studies reflect the contextual reality in Pakistan. In a study conducted in the Punjab province of Pakistan, Mumtaz and Salway discovered that strong societal pressures dictate men's low level of participation in the entire reproductive process. ${ }^{7}$ Men are expected not to spend 'too much time' with their wives. Instead, a 'real man' should keep the company of other men. In a joint family household, which is the prevalent form of households in Pakistan, men are encouraged not to take 'too much interest' in their wives and their 'pregnant condition'. Pregnant women are seen as impure and polluting and are forbidden from praying or handling the Qur'an (the holy book for Muslims) in the postpartum period; thus, they are off limits to men as well. Men's role in maternal care is limited to calling for the skilled attendant when it is time for the birth, arranging transport and providing the necessary financial resources. At the time of the birth, older male relatives will often be involved in this process as well, keeping the husband distanced so that it does not appear that he is overly concerned for his wife. Based on Mumtaz and Salway's study, ${ }^{7}$ husbands continue to play a limited role in maternal care in contemporary Pakistan; however, the involvement of mothers-inlaw tells a different story.

\subsection{Role of mothers-in-law in maternal health care}

Many studies have investigated the mother-in-law's role in maternal care in Asian and African countries., ${ }^{2,3,7}$ Several commonalities are found in such studies, including how decisionmaking authority frequently rests with the mother-in-law. In a study conducted in Mali, White et al. indicated that mothers-inlaw who followed cultural beliefs and practices were negatively associated with institutional delivery and postnatal care. ${ }^{3}$ This suggests that mothers-in-law may have a strong influence on whether a pregnant woman receives any maternal care. Similarly, a study by Simkhada et al. in Nepal (which, like Pakistan, is a patriarchal society) found that elderly women often occupy the top position. ${ }^{21}$ Mothers-in-law deal with matters related to pregnancy and make all the associated decisions. In this Nepal study, thirty women, ten husbands and ten mothers-in-law were interviewed. All the mothers-in-law were illiterate and over 60 years of age. For the most part, mothers-in-law saw no use for antenatal care or institutional delivery and did not support their daughters-in-law in this regard. Those mothers-in-law who did allow their daughtersin-law to receive antenatal care insisted that the housework be completed first. Mothers-in-law also had greater control over finances due to their close relationships with their husband and sons. The findings of the Nepal study also highlighted how lack of resources to pay for antenatal care of daughters-in-law influenced whether she would receive any Antenatal care or not. Likewise, in Mumtaz and Salway' Pakistan study, mothers-in-law typically have the authority to make decisions about maternal health care because they are considered to be wise and experienced, knowing what is best for their daughter-in-law. ${ }^{5}$ The Pakistan mother-inlaw is responsible for all maternal health care, and she will normally make all binding decisions regarding her daughter-inlaw's health care. It would appear that a woman's role in this process is to be quiet and obedient and not to express her personal desires.

Women's submission is an essential component of femininity; in other words, 'how a good woman behaves'. Whether a motherin-law will agree to provide maternal care for her daughter-in-law, however, is related to many other factors, including her own experience, her cultural beliefs and her relationship with her daughter-in-law, which tends to be a negative one. Therefore, it is important to understand the dynamics of the multiple relationships in and around an expectant mother and how the husband, wife and mother-in-law communicates and directly influences decisions on type of care received, be that professional or otherwise.

\subsection{Interfamilial relationships}

Although it has been highlighted that the mother-in-law may exert the most power and influence in relation to maternal care, this is not to say that the daughter-in-law has no influence whatsoever. $^{7}$ The quality of a woman's relationship with her husband, mother-in-law, marital family and natal family plays a significant role in whether she is able to access maternal care. Stronger women with a network of ties and better relationships are more able to negotiate better care for themselves. ${ }^{7}$ For example, a woman may appeal to her own mother to lobby her mother-in-law to provide antenatal care. Although Mumtaz and Salway did not investigate these relationships, they did include an index that evaluated a woman's communication with her husband. They found that women with higher scores for open and regular communication with their husband was positively associated with 
antenatal care. $^{7}$ Therefore, in this study we aimed to investigate the factors determining take-up of antenatal care and institutional delivery that are specifically related to the woman, her husband and her mother-in-law.

\subsection{Research questions}

The review of the literature has revealed that the concept of BPCR has been studied in several countries and from several perspectives. However, fewer studies have investigated the influence of interfamilial relationships on BPCR. It is crucial to explore the role of family relationship dynamics in BPCR. This study therefore posed the following questions.

1. What is the current level of antenatal care in the Khyber Pakhtunkhwa province of Pakistan?

2. What roles do the various family members play in decisionmaking about BPCR?

3. Who is the key player in this decision-making process?

4. Do these roles vary according to the demographic characteristics of the individuals involved in the decision-making process, such as education, location, profession and income?

\section{Methodology}

This study is a cross-sectional exploratory study. The data for the study was collected through a survey. Surveys are suitable for use in exploratory studies where the aims are to gain insight into the phenomena and relationships under study and understand in detail what respondents have in their mind. ${ }^{22}$ In the current study, Statistical Package for the Social Sciences (SPSS) version 13.0 was selected for conducting the analysis using logistic regression and descriptive statistics.

\subsection{Ethics}

The Project is funded by the Higher Education Commission of Pakistan and approved by the Institute of Management Sciences' ethics, procurement and research committees. A broad-based consent of the health department, Government of KPK, Health Care Commission, KPK and Health Regulatory Authority, KPK was obtained. The publication of the paper will not circulate any personal information of the respondents. The data has been collected through scientific procedures by female enumerators and efforts have been made to avoid any personal sway of the researchers which could influence the results. The content of the paper is also in compliance with plagiarism policy of the Institute of Management Sciences, Peshawar.

\subsection{The questionnaire}

Exploratory studies usually involve different methods of conducting questionnaires. The questionnaire that was used for this study incorporated standardized questions and were on categorical scale. Most of the questions were based on the JHPIEGO shared responsibilities matrix for BPCR. ${ }^{12}$ The JHPIEGO manual establishes a set of indicators for the assessment and monitoring of safe motherhood programs. This intervenes at six different levels, including, individual woman, her family (husband/partner), the health facility, the community, the provider, and the policymaker. Moreover, the manual also provides an inclusive set of tools for deriving these indicators and tracking progress. These standardized set of indicators in JHPIEGO manual could therefore be used across the countries for the safe monitoring of motherhood programs following the BPCR approach. ${ }^{23}$

\subsection{Target population and sampling frame}

The target population for the study included pregnant women in the Khyber Pakhtunkhwa province of Pakistan. Sampling was undertaken within the target population for the study; Khyber Pakhtunkhwa province in Pakistan, which is divided into seven administrative regions: Peshawar, Mardan, Malakand, Hazara, Kohat, Bannu and Dera Ismail Khan. A statistically representative sample was required so that the findings could be generalized to the population with an acceptable level of confidence. However, there was no accurate record of the target population from which a sample could be drawn which limited the ability to draw a perfect random sample. Therefore, the sample was based on systematic cluster sampling where the whole population was divided into clusters and then sample was selected from these clusters. The snowball technique, a form of non-probability sampling technique, was used for respondents within the clusters.

All seven administrative regions of Khyber Pakhtunkhwa were included in the sample to give geographical spread and provide equal opportunity of representation to the population. In the second stage of sampling, one district was selected randomly from each division. In the third stage, two union councils were randomly selected from within each of the selected districts: one from a rural area and one from an urban area. In the fourth stage, a primary sampling unit (PSU) was selected from within each union council. The PSU was selected based on the largest population cluster within the union council. The multistage cluster sampling gave a total of 14 PSUs in Khyber Pakhtunkhwa.

To avoid variability within the sample, according to social research practice a minimum of 30 respondents in each PSU within a district were likely to be interviewed in one cluster (PSU). This would have brought the total sample size to 420 (i.e., 30 each in 14 PSUs). However, given the nature of the study and the respondents, a relatively larger sample size was considered, comprising 50 respondents in each PSU within a district. This brought the total sample size to 700 (50 respondents in each of the 14 PSUs).

The proportion of pregnant women in the population of Pakistan is $4 \%$. Based on this statistic, the cluster size needed to be around 180 households in order to be able to find the desired number of respondents to provide a power to give generalizable findings. However, considering the heterogeneity of families in Khyber Pakhtunkhwa in terms of size, fertility rate and the chances of respondents not being available at the time of interview, the number of households in a PSU was standardized at 200.

\section{Results}

\subsection{Socio-demographic characteristics of respondents}

The socio-demographic characteristics of the 700 pregnant women who responded to the study are shown in Table 1 . The respondents represented rural and urban areas of the Khyber Pakhtunkhwa province in Pakistan. About $40 \%$ of them belonged to rural areas, whereas the remaining 60\% were from urban areas. More than half (54.4\%) of the women were uneducated, while most of the remaining $45.6 \%$ had attained a primary or secondary level of education. Of the husbands, $26 \%$ of them had no education at all, $56.5 \%$ had a primary to intermediate level of education and $17.5 \%$ had attained a higher level of education. The majority (92\%) of the mothers-in-law had never been to school, while most of the remaining $8 \%$ had attained a primary to secondary level of education.

The majority (94.1\%) of the women were housewives, while most of the husbands were employed. Many of the husbands were skilled labourers, unskilled labourers or employed by public or 
Table 1

Socio-demographic characteristics of respondents.

\begin{tabular}{|c|c|c|}
\hline Variable & Frequency & Percentage \\
\hline \multicolumn{3}{|l|}{ Area } \\
\hline Rural & 280 & 40.0 \\
\hline Urban & 420 & 60.0 \\
\hline \multicolumn{3}{|l|}{ Education level of wife } \\
\hline Illiterate (cannot read or write) & 346 & 49.4 \\
\hline Can read and write (no grade) & 35 & 5.00 \\
\hline School level (i.e., primary, middle, matric) & 231 & 33.0 \\
\hline Intermediate & 33 & 4.70 \\
\hline Graduation/degree & 35 & 5.00 \\
\hline Master's & 20 & 2.90 \\
\hline \multicolumn{3}{|l|}{ Education level of husband } \\
\hline Illiterate (cannot read or write) & 162 & 23.4 \\
\hline Can read and write (no grade) & 18 & 2.60 \\
\hline School level (i.e., primary, middle, matric) & 320 & 46.1 \\
\hline Intermediate & 72 & 10.4 \\
\hline Graduation/degree & 78 & 11.3 \\
\hline Master's & 43 & 6.20 \\
\hline \multicolumn{3}{|l|}{ Educational level of mother-in-law } \\
\hline Illiterate (cannot read or write) & 597 & 89.2 \\
\hline Can read and write (no grade) & 19 & 2.80 \\
\hline School level (i.e., primary, middle, matric) & 49 & 7.3 \\
\hline Intermediate & 2 & 0.30 \\
\hline Graduation/degree & 1 & 0.20 \\
\hline Master's & 1 & 0.20 \\
\hline \multicolumn{3}{|l|}{ Profession of wife } \\
\hline Housewife & 659 & 94.1 \\
\hline Public-sector employee & 18 & 2.60 \\
\hline Private-sector employee & 10 & 1.40 \\
\hline Student & 2 & 0.30 \\
\hline Farmer & 2 & 0.30 \\
\hline Self-employed & 7 & 1.00 \\
\hline Housemaid & 2 & 0.30 \\
\hline \multicolumn{3}{|l|}{ Profession of husband } \\
\hline Farmer & 44 & 6.10 \\
\hline Skilled labourer & 135 & 20.6 \\
\hline Unskilled labourer & 76 & 11.2 \\
\hline Public-sector employee & 85 & 15.0 \\
\hline Private-sector employee & 6 & 12.6 \\
\hline Student & 144 & 0.90 \\
\hline Self-employed & 36 & 21.7 \\
\hline Unemployed (dependent on family) & 101 & 5.30 \\
\hline Working abroad & 19 & 6.70 \\
\hline \multicolumn{3}{|l|}{ Family structure } \\
\hline Joint & 407 & 60.6 \\
\hline Nuclear & 221 & 32.9 \\
\hline Extended & 44 & 6.50 \\
\hline \multicolumn{3}{|l|}{ Stage of pregnancy } \\
\hline First trimester & 190 & 27.1 \\
\hline Second trimester & 247 & 35.3 \\
\hline Third trimester & 263 & 37.6 \\
\hline \multicolumn{3}{|l|}{ Age at the time of marriage } \\
\hline$\leq 15$ & 37 & 5.20 \\
\hline $16-20$ & 371 & 54.0 \\
\hline $21-25$ & 227 & 34.0 \\
\hline $26-30$ & 43 & 6.30 \\
\hline $31-35$ & 4 & 0.50 \\
\hline \multicolumn{3}{|l|}{ Age of the respondent (years) } \\
\hline$<15$ & 3 & 0.4 \\
\hline $16-20$ & 85 & 12.4 \\
\hline $21-25$ & 203 & 29.5 \\
\hline $26-30$ & 217 & 31.6 \\
\hline $31-35$ & 110 & 16.0 \\
\hline 36 and above & 69 & 10.0 \\
\hline
\end{tabular}

private-sector organizations. Some were self-employed, while others $(6.7 \%)$ were working abroad.

Most of the respondents (60.6\%) were living in a household with a joint family system. However, there were also nuclear (32.9\%) and extended (6.5\%) families. The most common age group for women at the time of marriage was $16-20$ years (54\%), followed by $21-25$ years (34\%). A small proportion (5.2\%) got married before they were 15 years old. With regard to their pregnancy, $37.6 \%$ of the women were in the third trimester, $35.3 \%$ in the second and $27.1 \%$ in the first.

\subsection{Uptake of antenatal care}

As shown in Table 2, 86.3\% of the respondents had received antenatal care during their current pregnancy. The main reasons for not obtaining antenatal care were reported to be as follows: being forbidden to give birth outside the home for religious reasons, female staff not being available, disrespectful staff and poor services at health facilities, and the husband not allowing it. Similar findings, related to distance to ANC venue, transport difficulties and lack of support from family (particularly, identified in many focus groups and during interviews with health professionals) were also reported in a study by Sumankuuro et al. ${ }^{24,25}$ conducted in two districts of Upper West region of Ghana.

\subsection{Institutional delivery and the role of family members}

Most of the respondents reported that they and their families were planning to give birth at an institution of some kind. As shown in Table 3a, a large percentage of the women $(47.8 \%)$ planned to give birth at a public hospital and $28.7 \%$ expected to attend a private clinic. A small proportion (11\%) planned to give birth at home.

In most cases, the decision on the place of delivery was made by the husband, the husband and wife jointly or the mother-in-law (see Table $3 \mathrm{~b}$ ). In the table, the figures suggest that the mother-inlaw has more influence than the woman and the husband is the one with the biggest role in making this decision.

\subsection{Role of the mother-in-law in obtaining antenatal care}

The role of the mother-in-law in obtaining antenatal care for the respondents was examined through binary logistic regression (see Table 4). For the interpretation of results, un-standardized coefficients were used. A positive significant relationship was found between receiving antenatal care and women's relationship with their mother-in-law.

\subsection{Power hierarchy in the family}

The respondents were asked to rank six family members from 1 to 6 in order of the amount of power they have in the family. As shown in Table $5,58.5 \%$ of the respondents considered their husband to be at the top of the power hierarchy, while $17.1 \%$ and $23.6 \%$ ranked him second and third, respectively. Similarly, $46.4 \%$ of the respondents ranked their father-in-law highest, $14.7 \%$ ranked their father-in-law second and $18.4 \%$ ranked him third. With regard to the mother-in-law, $22.1 \%$ of respondents ranked her first, $52.4 \%$ ranked her second and $21.8 \%$ ranked her third. The women most commonly ranked themselves fourth (39.4\%), followed by second in some families. Brothers-in-law and sisters-in-law were ranked lowest in the family power hierarchy. 
Table 2

Receipt of antenatal care and reasons for not seeking antenatal care.

\begin{tabular}{|c|c|c|}
\hline Variable & Yes $(\%)$ & No (\%) \\
\hline \multicolumn{3}{|l|}{ Reasons for not seeking antenatal care } \\
\hline I did not know where to go & 85.4 & 14.6 \\
\hline The facility is too far away & 85.4 & 14.6 \\
\hline It is too expensive & 50 & 50 \\
\hline There is no one to accompany me & 97 & 3 \\
\hline The service is not good & 98 & 2 \\
\hline There is family tradition of not going outside & 92.7 & 7.3 \\
\hline My husband did not allow it & 94.8 & 5.2 \\
\hline My mother-in-law did not allow it & 91.7 & 8.3 \\
\hline No female doctors/staff are available & 94.8 & 5.2 \\
\hline It is forbidden in religion to give birth outside the home & 100 & 0 \\
\hline Transport was not available & 92.7 & 7.3 \\
\hline The staff at the health facility do not treat women with respect & 98.9 & 1.1 \\
\hline I am afraid to go to the health facility & 95.8 & 4.2 \\
\hline I cannot spare the time because of the housework & 69.8 & 30.2 \\
\hline
\end{tabular}

Table 3a

Place of delivery.

\begin{tabular}{lcl}
\hline Option & Percentage & Frequency \\
\hline Respondent's home & 11 & 55 \\
TBA's home & 1 & 5 \\
Other home & 0.6 & 3 \\
Public health centre & 6.8 & 34 \\
Public hospital & 47.8 & 238 \\
Private clinic & 28.7 & 143 \\
Other & 2.8 & 14 \\
Do not know & 1.2 & 6
\end{tabular}

Table 3b

Role of family members in institutional delivery.

\begin{tabular}{lcl}
\hline Option & Percentage & Frequency \\
\hline No decision has been made & 3.6 & 18 \\
Respondent & 7.5 & 37 \\
Respondent and husband jointly & 26.5 & 131 \\
Husband & 33.5 & 166 \\
Respondent's mother & 2.2 & 11 \\
Respondent's father & 0.4 & 2 \\
Friend/neighbour & 0.2 & 1 \\
Health professional & 0.8 & 4 \\
Mother-in-law & 23.8 & 118 \\
\hline
\end{tabular}

\subsection{Socio-demographic characteristics and receipt of antenatal care}

To examine the association between socio-demographic characteristics and use of antenatal care services, bivariate logistic regression analysis was conducted. The demographic variables were as follows: region (rural vs urban); woman's level of education; husband's level of education; mother-in-law's level of education; woman's profession; husband's profession; income; family structure; and age of the woman at the time of marriage. The dependent variable was the use of antenatal care during current pregnancy, which was measured using a dichotomous scale (yes or no). Positive significant associations were found between receiving antenatal care and the following factors: a woman's level of education; her husband's level of education; her husband's profession; and her family income. However, no association was found between receiving antenatal care and the following factors: region; the mother-in-law's level of education; a woman's profession; family structure; and a woman's age at the time of marriage (Table 6).

\section{Discussion}

The results of this study indicate that there has been a significant increase in the uptake of antenatal care by women in the Khyber Pakhtunkhwa province of Pakistan. The percentage of women receiving antenatal care services $(86.3 \%)$ is much higher than shown by previous results $(60.5 \%) .{ }^{15}$ Similarly, there is has been a significant increase in the percentage of women planning to give birth in a health institution of some kind. Just under $84 \%$ of women reported to have planned for the delivery to take place in hospitals or clinics, which is more than double the figure shown in previous results $(40.5 \%) .{ }^{15}$ The significant increase in antenatal care and institutional delivery may be attributed to increased awareness among women and their families and government initiatives such as cash incentives, the Maternal Newborn and Child Health programme and the Lady Health Worker programme.

There is also more involvement of husbands and wives in the decision-making about maternal health care. The role of the mother-in-law is still quite visible, but the results suggest that it has become less influential than was reported by similar studies in the past. ${ }^{3,7,21}$ However, the relationship between a woman and her mother-in-law had a significant influence on the woman's uptake of antenatal care. Women who enjoyed a good relationship with their mother-in-law were more likely to receive antenatal care than those who did not have a good relationship with their motherin-law. The respondents reported that the father-in-law had a key position in the power hierarchy, but his role was less prominent in the maternal health issues of daughters-in-law.

The significant relationship between the levels of education of women and their husbands and the uptake of antenatal care highlights the crucial role of education. Previous studies also found an association between women's level of education and antenatal care, as well as with institutional delivery. ${ }^{13}$ Educated women and men are more aware of the importance of maternal health care. Educated women are more confident and approach problems in a

Table 4

Binary logistic regression: role of mother-in-law in receiving antenatal care.

\begin{tabular}{|c|c|c|c|}
\hline Option & $\mathrm{B}$ & S.E. & Sig. \\
\hline My mother-in-law did not allow me to receive antenatal care. & 0.245 & 0.296 & 0.408 \\
\hline I enjoy a good relationship with my mother-in-law. & 1.496 & 0.383 & 0.000 \\
\hline
\end{tabular}


Table 5

Power hierarchy in the family.

\begin{tabular}{|c|c|c|c|c|c|c|c|c|c|c|c|c|}
\hline \multirow[t]{3}{*}{ Family member } & \multicolumn{12}{|c|}{ Rank (\%) } \\
\hline & \multicolumn{2}{|l|}{1} & \multicolumn{2}{|l|}{2} & \multicolumn{2}{|l|}{3} & \multicolumn{2}{|l|}{4} & \multicolumn{2}{|l|}{5} & \multicolumn{2}{|l|}{6} \\
\hline & ${ }^{*} \mathrm{~F}$ & $\%$ & ${ }^{*} \mathrm{~F}$ & $\%$ & ${ }^{*} \mathrm{~F}$ & $\%$ & $* \mathrm{~F}$ & $\%$ & ${ }^{*} \mathrm{~F}$ & $\%$ & ${ }^{*} \mathrm{~F}$ & $\%$ \\
\hline Husband & 367 & 58.5 & 107 & 17.1 & 148 & 23.6 & 5 & 0.8 & 0 & 0.0 & 0 & 0.0 \\
\hline Father-in-law & 174 & 46.4 & 55 & 14.7 & 69 & 18.4 & 47 & 12.5 & 23 & 6.1 & 7 & 1.9 \\
\hline Mother-in-law & 96 & 22.1 & 228 & 52.4 & 95 & 21.8 & 11 & 2.5 & 3 & 0.7 & 2 & 0.5 \\
\hline Wife (respondent) & 9 & 1.8 & 160 & 32.3 & 80 & 16.2 & 195 & 39.4 & 45 & 9.1 & 6 & 1.2 \\
\hline Brother-in-law & 20 & 6.5 & 3 & 1 & 7 & 2.3 & 39 & 12.7 & 79 & 25.6 & 160 & 51.9 \\
\hline Sister-in-law & 4 & 1.2 & 5 & 1.5 & 47 & 13.8 & 72 & 21.2 & 146 & 42.9 & 66 & 19.4 \\
\hline
\end{tabular}

" $F$ ' represents frequency of the responses.

Table 6

Binary logistic regression: socio-economic characteristics and antenatal care.

\begin{tabular}{lccc}
\hline Demographic characteristic & Coefficient & S.E. & Significance \\
\hline Region & 0.099 & 0.259 & 0.703 \\
Woman's education & 1.042 & 0.368 & 0.005 \\
Husband's education & 0.678 & 0.78 & 0.015 \\
Mother-in-law's education & -0.935 & 0.565 & 0.098 \\
Women's profession & 0.324 & 0.823 & 0.694 \\
Husband's profession & 0.114 & 0.057 & 0.044 \\
Family structure & 0.000 & 0.001 & 0.918 \\
Age of the woman upon marriage & -0.001 & 0.001 & 0.068 \\
Monthly income & 0.387 & 0.129 & 0.003 \\
\hline
\end{tabular}

more positive manner. ${ }^{7}$ They can more easily convince members of their family about the importance of health care. Moreover, no relationship was found between the uptake of antenatal care and the mother-in-law's education.

The significant positive relationship between antenatal care and income indicates that financial capacity is an important determinant of the use of antenatal care. This finding is consistent with the study by Mumtaz and Salway ${ }^{7}$ in the Punjab province of Pakistan. According to them, people in poverty must prioritize their needs and antenatal care is given a lower priority than basic needs, such as food and shelter.

\section{Limitations}

As far as limitations of the study are concern, the participants shyness was major obstacle to get deep insight of the respondents on frequently prevailed medical conditions during antenatal phase. This was possibly due to low literacy level and cultural barriers to discuss maternal health issues with outsiders (i.e., female enumerators). Although enumerators were trained staff even then, it has observed the language and adherence issue to the contents been asked. There were also security and access issues. Moreover, no qualitative data was collected and analysed which would have provided more depth and breadth to our understanding to the contextual relationship dynamics and how they operate to both build barriers and facilitate access to available maternity care provision.

\section{Conclusion}

It can be concluded that the use of antenatal care and institutional delivery services has increased in the Khyber Pakhtunkhwa province of Pakistan. However, there is still much room for improvement. More intervention is required by the Pakistan government to increase awareness and uptake of antenatal care, especially among the many families who are in poverty as improving financial situation for families or the women is very critical for a sustained use of BPCR. The three main decisionmakers identified in this study - that is, women, husbands and mothers-in-law - should be the focus of campaigns on antenatal care. Furthermore, since education has proved to be a crucial element in the use of antenatal care, the Pakistan government needs to pay more attention to this element, especially among women. It is also crucial that maternity care providers in Pakistan, midwives, medical staff and nurses, are aware of these challenges because as direct stakeholders they can actively contribute to the moral, motivational and cultural alignment with these three identified decision makers (i.e. women, husband and mother-inlaw). Enhancing antenatal care and education awareness is an important part of the work required to curtail the morbidity and mortality rate associated with maternity and helps meet WHO millennium development goals (MDG) set for developing countries such as Pakistan. ${ }^{26,27,28}$

\section{Acknowledgements}

The study has been fully funded by the Higher Education Commission of Pakistan under the National Research Program for Universities (NRPU).

\section{References}

1. Nanjala M., Wamalwa D. Determinants of male partner involvement in promoting deliveries by skilled attendants in Busia, Kenya. Glob J Health Sci 2012:4(2):60-7.

2. White D, Dynes M, Rubardt M, Sissoko K, Stephenson R. The influence of intrafamilial power on maternal health care in Mali: perspectives of women, men and mothers-in-law. Int Perspect Sex Reprod Health 2013;39(2):58-68.

3. Agha S, Carton TW. Determinants of institutional delivery in rural Jhang, Pakistan. Int J Equity Health 2011;10(1):1-12.

4. Hogan MC, Foreman KJ, Naghavi M, Ahn SY, Wang M, Makela SM, et al. Maternal mortality for 181 countries, 1980-2008: a systematic analysis of progress towards Millennium Development Goal 5. Lancet 2010;375 (9726):1609-23.

5. Ronsmans C. Maternal mortality in developing countries. In: Semba RD, Bloem MW, editors. Nutrition and health in developing countries. 2nd Ed. Totowa: Humana Press; 2008. p. 31-56.

6. Jokhio AH, Winter HR, Cheng KK. An intervention involving traditional birth attendants and perinatal and maternal mortality in Pakistan. $N$ Engl J Med 2005;352(May (20)):2091-9.

7. Mumtaz Z, Salway SM. Gender, pregnancy and the uptake of antenatal care services in Pakistan. Sociol Health Illn 2007;29(1):1-26.

8. Hakim A, Salway S, Mumtaz Z. Womens autonomy and uptake of contraception in Pakistan. Asia Pac Popul J 2003;18(March (1)):63-82.

9. Khan A. Mobility of women and access to health and family planning services in Pakistan. Reprod Health Matters 1999;7(November (14)):39-48.

10. Mumtaz K, Rauf F. Inter-and intra-generational knowledge transfer and zones of silence around reproductive health in Sunnakhi. In: Harcourt W, editor. Power, reproduction and gender: the intergenerational transfer of knowledge. . p. 98-119.

11. Iliyasu Z, Abubakar IS, Galadanci HS, Aliyu MH. Birth preparedness, complication readiness and fathers' participation in maternity care in a northern Nigerian community. Afr J Reprod Health 2010;14(1):21-32.

12. JHPIEGO. Monitoring birth preparedness and complication readiness. Tools and indicators for maternal and newborn health. Baltimore, MD: JHPIEGO; 2004.

13. United Nations Development Programme (UNDP). A social determinants approach to maternal health. New York, NY: UNDP; 2011. 
G Model

WOMB 780 No. of Pages 8

8

U. Ghani et al./Women and Birth $x x x$ (2018) $x x x-x x x$

14. National Institute of Population Studies (NIPS) [Pakistan], Macro International Inc. Pakistan demographic and health survey 2006-7. Islamabad, Pakistan: NIPS and Macro International Inc.; 2008.

15. National Institute of Population Studies (NIPS) [Pakistan], ICF International. Pakistan demographic and health survey 2012-13 preliminary report. Islamabad, Pakistan and Calverton, MD: NIPS and ICF International; 2013.

16. Khan MA, Mirza S, Ahmed M, Rushed A, Khan A, Wally J, et al. Making birthing safe for Pakistan women: a cluster randomized trial. BMC Pregnancy Childbirth 2012;12(1):67.

17. Ha Z, Hafeez A, Khanum A, Southhall D. Birth preparedness and the role of the private sector: a community survey. J Pal Med Assoc 2009;59(5):302-6.

18. Bloom SS, Wypij D, Gupta MD. Dimensions of women's autonomy and the influence on maternal health care utilization in a north Indian city. Demography 2001;38(February (1)):67-78.

19. Bhatta DN. Involvement of males in antenatal care, birth preparedness, exclusive breast feeding and immunizations for children in Kathmandu, Nepal. BMC Pregnancy Childbirth 2013;13(14):1-7.

20. Kakaire O, Kaye DK, Osinde MO. Male involvement in birth preparedness and complication readiness for emergency obstetric referrals in rural Uganda. Reprod Health 2011;8(1):1-7.

21. Simkhada B, Porter MA, Van Teijlingen ER. The role of mothers-in-law in antenatal care decision-making in Nepal: a qualitative study. BMC Pregnancy Childbirth 2010;10(1):34.
22. Saunders M, Lewis P, Thornhill A. Research methods for business students. 5 th ed. Harlow, Essex: Pearson Education; 2009.

23. Del Marco RC. Monitoring birth preparedness and complication readiness. Tools and indicators for maternal and newborn health. JHPIEGO: [104_TD\$DIFF] [98_TD\$DIFF]Baltimore, Maryland; 2004 [330] p. (USAID Award No. HRN-0098-00043-00).

24. Sumankuuro J, Crockett J, Wang S. The use of antenatal care in two rural districts of Upper West Region, Ghana. PLo One 201712(September (9)) e0185537.

25. Sumankuuro J, Crockett J, Wang S. Maternal health care initiatives: causes of morbidities and mortalities in two rural districts of Upper West Region, Ghana. CLoS One 201712(August (8))e0183644.

26. Frank J, Chen L, Bhutto ZA, Cohen J, Crisp N, Evans T, et al. Health professionals for a new century: transforming education to strengthen health systems in an interdependent world. Lancet 2010;376(December (9756)):1923-58.

27. Sarfraz M, Humid S. Challenges in delivery of skilled maternal care experiences of community midwives in Pakistan. BMC Pregnancy Childbirth 2014;14(February (1)):59.

28. Thomson M, Kentikelenis A, Stubs T. Structural adjustment programmes adversely affect vulnerable populations: a systematic-narrative review of their effect on child and maternal health. Public Health Rev 2017;38(July (1)):13.

Please cite this article in press as: U. Ghani, et al., The significance of interfamilial relationships on birth preparedness and complication readiness in Pakistan, Women Birth (2018), https://doi.org/10.1016/j.wombi.2018.03.005 